\title{
Laparoscopic Rectopexy; Is It Useful for Persistent Rectal Prolapse in Children?
}

\author{
Medhat M. Ibrahim 1*, Mohammed Abd El Razik1, Ahmed M. Abdelkader² \\ ${ }^{1}$ Pediatric Surgery Unit, Faculty of Medicine, Al-Azhar University, Nasr City, Cairo, Egypt \\ ${ }^{2}$ General Surgery Unite RCMC, Yanbu Industrial City, KSA \\ Email: ${ }^{*}$ dr medhat ibrahem@yahoo.com
}

Received 6 February 2014; revised 5 March 2014; accepted 13 March 2014

Copyright (c) 2014 by authors and Scientific Research Publishing Inc.

This work is licensed under the Creative Commons Attribution International License (CC BY). http://creativecommons.org/licenses/by/4.0/

(c) ()

\begin{abstract}
Introduction: Rectal prolapse is a relatively common, usually self-limiting illness in children. Peak incidence is between 1 and 3 years. The intervention is required for the persistent rectal prolapse (PRP). Only scanty experience is available with laparoscopic rectopexy in children. There is no available work using both mesh and suture laparoscopic rectopexy in literature. This work is unique that it presents our clinical experience with both mesh and suture laparoscopic rectopexy in children. This is a prospective clinical study for the outcome of laparoscopic rectopexy (LRP) by both mesh and suture technique in children with persistent rectal prolapse (PRP). Materials and Methods: Fourteen cases of PRP were managed with LRP from February 2008 to August 2012. Results: Of the 14 children, $10(71.42 \%)$ were males and $4(28.57 \%)$ were females. Male to female ratio was 2:1. The mean age of presentation was 5 years (range 3 - 8 years). The presenting complaints were mass descending per rectum along with bleeding per rectum lasting from 1 to 3 years. All had rectal prolapse of $5-7 \mathrm{~cm}$ in length. 12 out of 14 children had recurrence even after sclerotherapy before referral to laparoscopic rectpexy. The mean duration of surgery was $\mathbf{3 0}$ minutes (range 20 - 60 minutes). No intraoperative complications were reported; only one case got constipation and was managed conservatively and no recurrence. Conclusion: LRP is safe, feasible in children and gives satisfactory results after failure of all conservative even sclerotherapy injection.
\end{abstract}

\section{Keywords}

Rectal Prolapse; Laparoscopy; Rectopexy

\footnotetext{
"Corresponding author.
} 


\section{Introduction}

Rectal prolapse is a relatively common, usually self-limiting illness in children. Peak incidence is between 1 and 3 years [1] [2]. It can be partial (protrusion of only mucosa from anal verge) or complete (full thickness of rectum is involved). The intervention is required for the persistent rectal prolapse (PRP). Laparoscopic rectopexy (LRP) is in vogue for adults; however, only scanty experience is available with this technique in children. We present our experience with LRP for PRP at the pediatric surgery unit.

\section{Materials and Methods}

This is a prospective clinical study of 14 children managed with LRP (mesh and suture techniques) for PRP from April 2008 to September 2012. The conservative management of nutritional support, bowel habit regulation, and dietary manipulation for managing the prolapse had failed in all cases and were referred for surgical intervention. 12 of the 14 patients were managed with sclerotherapy using ethanolamine oliat injected submucosally in three to four sittings before being referred to laparoscope rectopexy. Cases with rectal prolapse who did not respond to conservative management over 1 to 2 years were defined as PRP and were subjected to LRP. The decision to operate was based on the age of patient, duration of conservative management (>12 months) and frequency of recurrent prolapse (two or more episodes requiring manual reduction with or without sedation per month), along with symptoms of pain, rectal bleeding, edema, ulceration, difficult reduction and recurrent prolapse. The record of age, sex, weight, and initial presentation, duration of symptoms, precipitating events and co-morbidities was maintained. Preoperative evaluation included physical examination, routine laboratory investigation, plain X-Ray anterior-posterior \& lateral view, defecography and proctoscopy in all patients. The ethical committee approved the technique. Written consent was obtained from the family after full information about the surgery and the post-operative squeal.

All children were given enemas on the morning of the surgery. Prophylactic antibiotics were given at the time of induction of anesthesia. All were operated under general anesthesia with endotracheal intubation. After full anesthesia and under complete sterilization catheter inserted to evacuate the urinary bladder. Supra umbilical transverse skin incision was done for ENDOPATH XCEL port with 5-mm $0^{\circ}$ scope introduction to the peritoneum under vision on the laparoscope monitor, then $\mathrm{CO}_{2}$ insufflation to peritoneum up to $12 \mathrm{mmHg}$ intra-abdominal pressure was operand with hemodynamic and respiratory monitoring by anesthesia. Introduction of 5-mm, $30^{\circ}$ scope at umbilicus port and two 5-mm working ports in mid-clavicular line followed this over the line joining mid-inguinal point and both costal margins. The position of the working ports varied with the child height and abdominal cavity size, ensuring acceptable ergonomics according to the child body built. Trendelenburg position helped in moving away the small bowel from the operative field.

The rectosigmoid was grasped and mobilized after dividing the right side peritoneal fold starting from the sacral promontory (Figure 1) and make circumferentially dissection to create a cave between the sacrum and the rectum with out opening the left peritoneal fold (Figure 2). Both the ureters were identified and safe guarded. Rectum was mobilized from the sacral promontory to the lateral ligaments, and until the surface of the sacrum was clearly felt with an instrument and continue dissection down to the anal sphincter (Figure 3). The mesh was inserted between the rectum and the sacral surface (Figure 4). Rectum was then pulled up and fixed with the presacral fascia, mesh and the bone of sacral promontory of the sacrum on either side with two to three (2 cm

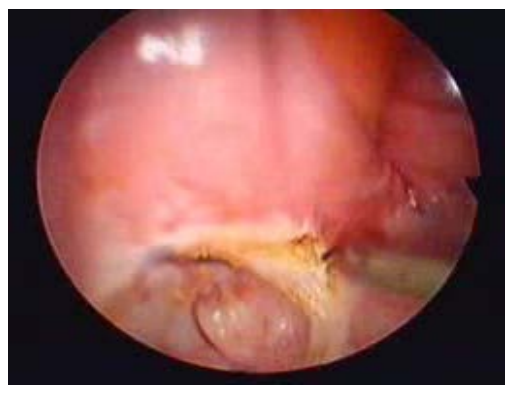

(a)

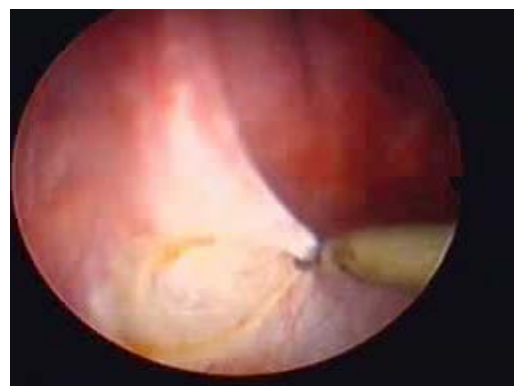

(b)

Figure 1. Dividing the right side peritoneal fold starting from the sacral promontory. 


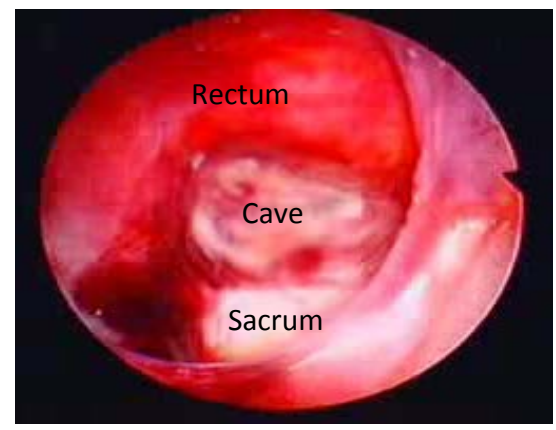

Figure 2. Circumferential dissection to create a cave between the sacrum and the rectum.

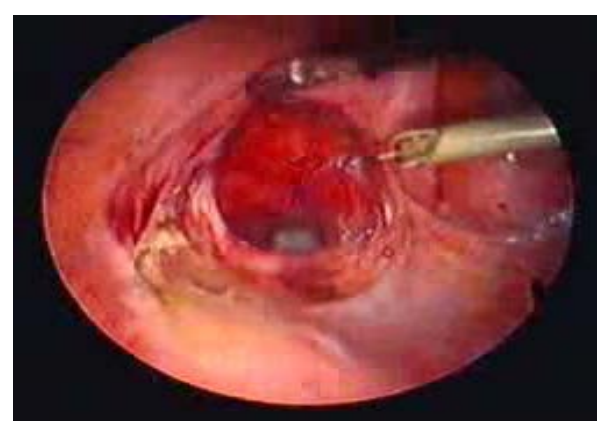

Figure 3. Dissection continued down to the anal sphincter.

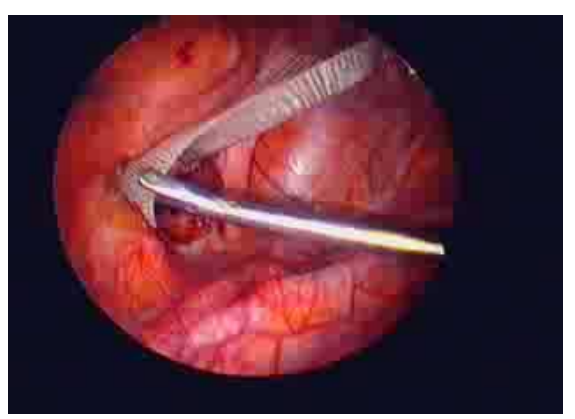

Figure 4. Mesh was inserted between the rectum and the sacral surface.

between each suture in the rectum) seromuscular sutures of PDS size 3/0 using intra-corporeal knotting (Figure 5). Closure of the right peritoneal window with interrupted $3 / 0$ absorbable suture was done to cover the mesh and close the cavity (Figure 6). Patients were kept nil orally till the return of bowel sounds. Postoperatively, stool softeners were routinely prescribed for at least 4 weeks.

\section{Results}

Of the 14 children, 10 (71.42\%) were males and 4 (28.57\%) were females. Male to female ratio was 2:1. The mean age of presentation was 5 years (range 3 - 8 years). The presenting complaints were mass descending per rectum along with bleeding per rectum lasting from 1 to 3 years. All had rectal prolapse of $5-7 \mathrm{~cm}$ in length. Two children were under neuro-psychiatric treatment and one had walking problem. The two children under neuro-psychatric treatment were males and weighted $17.4 \mathrm{~kg}$ and $18.2 \mathrm{~kg}$ at ages 7 years and 9 years, respectively. The child with walking problem was a female aged 6 years and weighted $13.8 \mathrm{~kg}$, which was below the 


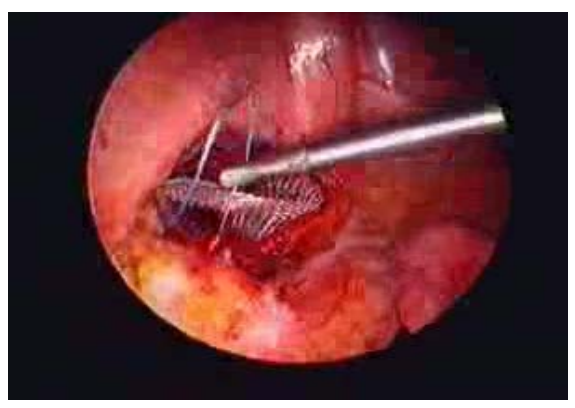

Figure 5. Rectum fixed with the presacralfascia, mesh and the bone of sacral promontory of the sacrum.

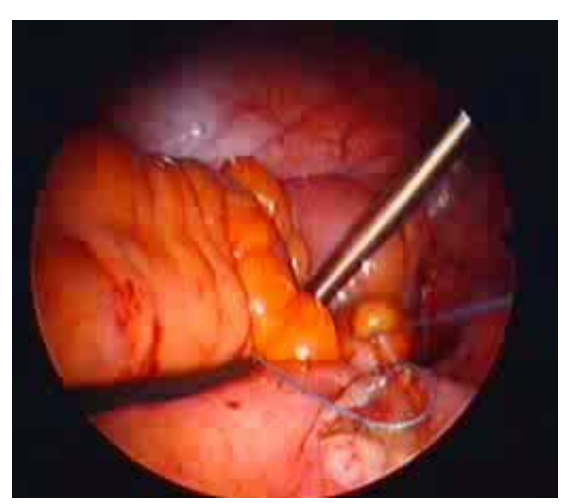

Figure 6. Closure of the right peritoneum reflection.

$5^{\text {th }}$ centile as per NCHS weight for age charts. The remaining 11 out of 14 children were normal in weight and fell between the $20^{\text {th }}$ and $50^{\text {th }}$ centile by NCHS standards.

The mean duration of surgery was 30 minutes (range 20 - 60 minutes). No intraoperative complications were reported. Redundancy of recto-sigmoid was noticed in all patients except the two with neuropsychiatric problem. Pelvic floor laxity was found in those two cases. No intraoperative problems were encountered and no case required conversion. Mean postoperative hospitalization was 3 days (range 2 - 5 days). All were followed up for an average of 10 months (range 4 - 12 months), with no recurrence reported in any caseduring the follow-up period. One child complained of postoperative constipation, which improved with dietary manipulation and stool softeners. Also there was no urinary or fecal control problems in all cases at the follow-up period.

\section{Discussion}

The exact etiology of rectal prolapse in children is unknown. They thought to be related to several anatomic considerations such as the vertical configuration of the sacrum, greater mobility of the sigmoid colon, and a loosely attached rectal mucosa to the underlying muscularis, and the absence of Houston's valves in approximately $75 \%$ of infants younger than 1 year of age [1]. Patients with rectal prolapse have lowered basal and squeeze pressures with anorectalmanometry than normal control subjects [3] [4]. Rectal prolapse usually presents as a self-limiting disorder in children younger than 4 years of age [5] [6]. In the pediatric population, the condition is usually diagnosed by the age of 3 years, with an equal sex distribution [7]. Male preponderance has been noted by Shalaby et al. [8] and our study reaffirmed a male preponderance with $70 \%$ of patients being males.

Mostly conservative treatment is successful [6]; however, the prolapse may persist indefinitely in some children, requiring surgical intervention. The percentage of children requiring surgical intervention, eventually, after failure of conservative management varies from $14 \%$ to $20 \%$ [9]. Surgery is indicated in rare cases with intractable rectal prolapse and may be considered in patients who are not spontaneously cured in 12 - 18 months of 
follow-up [9]. The mean period of conservative management in this study could actually be ascertained as this study was conducted at a tertiary care hospital, whereas the patients were managed from the start. However, a trial of at least 12 months of conservative management was given before the patients were referred to laparoscopic rectopexy.

Literature is replete with various procedures for this condition, which is a testimony to the lack of consensus over an ideal procedure. Broadly, the operative procedures can be classified as abdominal [10] or perineal [11][15]. Less invasive procedures include injection sclerotherapy [6] [16] [17] and encircling of the anus [18], with reported success rate of nearly $90 \%$ in different series. In this study all the above procedures were tried except anal-encircling procedure, which make our procedure an effective valuable method for management of the persistent rectal prolapse in children.

Abdominal rectopexy is advocated for the recurrent or PRP in children. In adults, in a recent meta-analysis comparing outcomes using the laparoscopic technique with an open procedure, no differences in operative morbidity and recurrence rates were found [19].

As experience is being gained in the pediatric cases with the laparoscopic approach, it has been shown to have good results [9] [20] [21]. Laparoscopic surgery has the advantages of good accessibility, butter visualization of the narrow pelvic space anatomy during surgery, less post-operative pain, shorter hospital stay and early recovery, as compared with laparotomy. Apart from these advantages, the results are similar to those with the open procedures irrespective of the method used (suture, resection or posterior mesh). Therefore, where expertise is available, this approach may be preferred [7].

Koivusalo et al. reported a median operation time of 80 minutes (range 62 - 90 minutes) for LSRP and a median hospital time of 6 days (range 3 - 8 days) [9]. Shalaby et al., in their study, reported the mean duration of surgery as 40 minutes (range 30 - 55 minutes). The mean hospitalization time was 3 days [8]. Experience with LRP in this study further reinforces these findings; also continuous laparoscopic use will improve the operative procedure, operative time, and make the hospital stay shorter. The mean duration of surgery was 30 minutes (range 20 - 60 minutes. No intraoperative complications were reported. Mean postoperative hospitalization was 6 days (range 4 - 10 days).

The recurrence rates reported for PRP are as much as $6.9 \%$ at 5 years and $10.8 \%$ at 10 years [8]. Recurrent cases can be treated by laparoscopic resection rectopexy with or without mesh [17] [21]. However, Rintala and Pakarinen prefer laparoscopic suspension of the rectum to anterior sacrum without mesh and they claimed that this approach is successful in several patients [9]. In this study, after a mean follow-up of 6 months, we had no recurrence because the sutures will fix the rectum strongly in the sacral promontory that acted as a dock, while the mesh is going to create a port for the rectum to seal over it.

Koivusalo [9] reported two patients with postoperative constipation. They added that constipation is the only postoperative problem and is frequently worsened. Shalaby et al. reported only one case of postoperative constipation out of 52 cases operated with laparoscopic mesh rectopexy [8]. In this study we had just one case of postoperative constipation which could be managed conservatively in spite of the longer use of the post-operative laxative and diet manipulation to prevent the constipation. This stands in stark contrast to high rate (35\%) of postoperative constipation reported earlier by Kariv et al. All our 14 children were bowel continent at the time of presentation and none of them had any continence issues in the postoperative setting.

Although this is a single center experience without a control group, the results are satisfactory. Whereas larger randomized control studies are required to secure conclusive evidence for the superiority of LRP over the conventional open procedure, paucity of PRP cases in a single center remains the limiting factor. We conclude that LRP is an effective and safe minimal invasive procedure alternative to the open procedures with similar success rates and no additional complications.

\section{References}

[1] Siafakas, C., Vottler, T.P. and Andersen, J.M. (1999) Rectal Prolapse in Pediatrics. Clinical Pediatrics, 38, 63-72.

[2] Qvist, N., Rasmussen, L., Klaaborg, K.E., Hansen, L.P. and Pedersen, S.A. (1986) Rectal Prolapse in Infancy: Conservative versus Operative Treatment. Journal of Pediatric Surgery, 21, 887-888. http://dx.doi.org/10.1016/S0022-3468(86)80015-X

[3] Gourgiotis, S. and Baratsis, S. (2007) Rectal Prolapse. International Journal of Colorectal Disease, 22, 231-243. http://dx.doi.org/10.1007/s00384-006-0198-2 
[4] Theuerkauf Jr., F.J., Beahrs, O.H. and Hill, J.R. (1970) Rectal Prolapse: Causation and Surgical Treatment. Annals of Surgery, 171, 819-835. http://dx.doi.org/10.1097/00000658-197006010-00002

[5] Corman, M.L. (1985) Rectal Prolapse in Children. Diseases of the Colon \& Rectum, 28, 535-539. http://dx.doi.org/10.1007/BF02554107

[6] Abes, M. and Sarihan, H. (2004) Injection Sclerotherapy of Rectal Prolapse in Children with 15 Percent Saline Solution. European Journal of Pediatric Surgery, 14, 100-102. http://dx.doi.org/10.1055/s-2004-815855

[7] Madiba, T.E., Baig, M.K. and Wexner, S.D. (2005) Surgical Management of Rectal Prolapse. Archives of Surgery, 140, 63-73. http://dx.doi.org/10.1001/archsurg.140.1.63

[8] Shalaby, R., Ismail, M., Abdelaziz, M., Ibrahem, R., Hefny, K., Yehya, A., et al. (2010) Laparoscopic Mesh Rectopexy for Complete Rectal Prolapsed in Children: A New Simplified Technique. Pediatric Surgery International, 26, 807813. http://dx.doi.org/10.1007/s00383-010-2620-7

[9] Koivusalo, A., Pakarinen, M. and Rintala, R. (2006) Laparoscopic Suture Rectopexy in the Treatment of Persisting Rectal Prolapse in Children: A Preliminary Report. Surgical Endoscopy, 20, 960-963. http://dx.doi.org/10.1007/s00464-005-0424-y

[10] Safar, B. and Vernava, A.M. (2008) Abdominal Approaches for Rectal Prolapse. Clinics in Colon and Rectal Surgery, 21, 94-99.

[11] Ashcraft, K.W., Garred, J.L., Holder, T.M., Amoury, R.A., Sharp, R.J. and Murphy, J.P. (1990) Rectal Prolapse: 17-Year Experience with the Posterior Repair and Suspension. Journal of Pediatric Surgery, 25, 992-995. http://dx.doi.org/10.1016/0022-3468(90)90245-5

[12] Pearl, R.H., Ein, S.H. and Churchill, B. (1989) Posterior Sagittal Anorectoplasty for Pediatric Recurrent Rectal Prolapse. Journal of Pediatric Surgery, 24, 1100-1102. http://dx.doi.org/10.1016/S0022-3468(89)80228-3

[13] Tsugawa, C., Matsumoto, Y., Nishijima, E., Muraji, T. and Higashimoto, Y. (1995) Posterior Plication of the Rectum for Rectal Prolapse in Children. Journal of Pediatric Surgery, 30, 692-693. http://dx.doi.org/10.1016/0022-3468(95)90692-4

[14] Wyatt, A.P. (1981) Perinealrectopexy for Rectal Prolapse. British Journal of Surgery, 68, 717-719. http://dx.doi.org/10.1002/bjs.1800681014

[15] Chwals, W.J., Brennan, L.P., Weitzman, J.J. and Woolley, M.M. (1990) Transanal Mucosal Sleeve Resection for the Treatmentof Rectal Prolapse in Children. Journal of Pediatric Surgery, 25, 715-718. http://dx.doi.org/10.1016/S0022-3468(05)80003-X

[16] Wyllie, G.G. (1979) The Injection Treatment of Rectal Prolapse. Journal of Pediatric Surgery, 14, 62-64. http://dx.doi.org/10.1016/S0022-3468(79)80578-3

[17] Fahmy, M.A. and Ezzelarab, S. (2004) Outcome of Submucosal Injection of Different Sclerosing Materials for Rectal Prolapse in Children. Pediatric Surgery International, 20, 353-356.

[18] Oeconomopoulos, C.T. and Swenson, O. (1960) Thiersch’s Operation for Rectal Prolapsed in Infants and Children. The American Journal of Surgery, 100, 457-461. http://dx.doi.org/10.1016/0002-9610(60)90388-3

[19] Purkayastha, S., Tekkis, P., Athanasiou, T., Aziz, O., Paraskevas, P., Ziprin, P., et al. (2005) A Comparison of Open vs Lap Abdominal Rectopexy for Full-Thickness Rectal Prolapse: A Meta-Analysis. Diseases of the Colon \& Rectum, 48, 1930-1940. http://dx.doi.org/10.1007/s10350-005-0077-x

[20] Saxena, A.K., Metzelder, M.L. and Willital, G.H. (2004) Laparoscopic Suture Rectopexy for Rectal Prolapse in a 22-Month-Old Child. Surgical Laparoscopy Endoscopy \& Percutaneous Techniques, 14, 33-34. http://dx.doi.org/10.1097/00129689-200402000-00009

[21] Bonnard, A., Mougenot, J.P., Ferkdadji, L., Huot, O., Aigrain, Y., De Lagausie, P., et al. (2003) Laparoscopic Rectopexy for Solitary Ulcer of Rectum Syndrome in a Child. Surgical Endoscopy, 17, 1156-1157. http://dx.doi.org/10.1007/s00464-002-4285-3 